\title{
The Risk of Prostate Cancer Associated With Common Mutations of $A R$ Gene in Iranian Population: a Perspective Study of Personalized Treatment
}

\section{Marzieh Rahbaran}

Islamic Azad University Tehran Medical Sciences

Maryam Hassani Doabsari

Islamic Azad University Tehran Medical Sciences

Farshad Sharifi

Tehran University of Medical Sciences Endocrinology and Metabolism Research Institute

Mahdi Afshari

Zabol University of Medical Sciences

Mandana Hasanzad ( $\sim$ mandanahasanzad@yahoo.com )

Islamic Azad University Tehran Medical Sciences https://orcid.org/0000-0002-0538-1135

\section{Research Article}

Keywords: Prostate cancer, Androgen receptor, Mutation, benign prostate hyperplasia, Radical prostatectomy, Sanger sequencing

Posted Date: December 29th, 2021

DOI: https://doi.org/10.21203/rs.3.rs-1185476/v1

License: (c) (i) This work is licensed under a Creative Commons Attribution 4.0 International License.

Read Full License 


\section{Abstract}

Background: Prostate cancer (PC) is one of the most common cancers among men. Genetic predisposition is emerging as a risk factor for PC development. The Androgen receptor $(A R)$ gene is associated with the development and prognosis of PC. Understanding the $A R$ mutations is very important in the precision treatment of PC-resistant patients to androgen deprivation therapy. In this study, we investigate any association between common $A R$ mutations with the risk of PC.

Methods and results: In this case-control study, blood samples were collected from 121 radical prostatectomy (RP) patients who were pathologically diagnosed with PC and 120 benign prostate hyperplasia (BPH) subjects as a control group. The targeted area of the AR gene was amplified by PCR and confirmed by the Sanger sequencing method. The target area of the AR gene screened for 124 alterations in intron 7, 44 mutations in exon 8, and 52 variants in the 3'UTR region. rs113528927 Dellns AC>ACACACCAC had the most frequent mutant alleles between case and control groups, but this genotype distribution among the two recruited groups was not significant. Only one mutation, c.2644C>A, was observed in exon 8 in BPH subjects, and six alterations were detected in $3^{\prime} U T R$.

Conclusions: For the first time in the Iranian population, $A R$ common mutations were screened in PC patients, and our results indicate no relationship with the risk of $P C$, which means that other potential molecular risk factors may be engaged for PC in our population.

\section{Introduction}

According to recent estimates of global cancer incidence, in men, PC globally is the most frequently diagnosed cancer, followed by lung, colorectal, and liver cancer. With regard to mortality, PC is the second cause of cancer death in men [1]. In Iran, also, it is categorized as the second leading cause of cancer death, following lung cancer, and is known as the third most common non-skin cancer among men [2, 3]. As a complex and multifactorial disease, age, family history, and genetic are the major risk factors involved in PC development [4]. Although the sporadic type of PC constitutes a considerable percentage of this disorder, a limited number of cases have been reported with familial and hereditary PC subtypes [5].

Several Genome-Wide Association Studies (GWASs) have been reported some candidate genes involved in the pathogenesis of $\mathrm{PC}$, including the androgen receptor $(A R)$ gene [6]. The $A R$ gene is located on Xq11.2-q12 with a length of more than $90 \mathrm{~kb}$ that is comprised of eight exons encoding four functional domains; N-terminal (transactivation) domain, DNA binding domain (DBD), hinge region, and carboxyterminal ligand-binding domain (LBD). AR encoded protein is a member of the steroid hormone receptor superfamily and a ligand-activated nuclear transcription factor $[4,6,7]$. As the specific ligands for AR, androgens are vital for many mechanisms, including the differentiation of male sex determination, development of the secondary characteristics of the male, and spermatogenesis [8]. After androgen binding to its receptor, the dimerized AR translocates to the nucleus and regulates the transcriptional 
output of many androgen-regulated genes like NKX3.1 and FOX family transcription factors, PSA, IGF1R, UBE2C, UGT2B15, KLK3, TMPRSS2, FKBP5, and some other genes [9].

Furthermore, AR is a pivotal drug target for PC treatment, especially in the castration-resistant (CRPC) forms. All current non-steroidal AR antagonists, such as Hydroxyflutamide, Bicalutamide, and Enzalutamide, target the receptor's androgen binding site, competing with endogenous androgenic steroids [10]. Several mutations in the AR gene, including loss of function, missense, nonsense, and frameshift, can produce dysfunctional AR protein and result in PC development, making a difference in prognosis [11-13]. Accordingly, several $A R$ mutations in LBD have been associated with poor prognosis and resistance to conventional PC treatments [10].

Mutations such as F877L and T878A (formerly F876L and T877A) were associated with resistance to Apalutamide, Enzalutamide, or the androgen biosynthesis inhibitor Abiraterone acetate, respectively [13, 14]. T878A is one of the most frequently known somatic mutations, producing a receptor capable of incomplete binding and activation by several steroid hormones and ligands, including estrogen, progestin, glucocorticoids several antiandrogens $[5,15-17]$. In this study, we aimed to investigate the association of $A R$-LBD common mutations with the risk of $\mathrm{PC}$ in Iranian men with radical prostatectomy (RP) and benign prostate hyperplasia (BPH) for the first time.

\section{Materials And Methods}

\section{Patients' characteristics:}

In this population-based case-control study, we recruited a total of 241 subjects who met the defined study criteria to investigate the association between LBD-AR gene common mutations and the risk of PC in the Iranian population. $121 \mathrm{RP}$ patients who were pathologically diagnosed with $\mathrm{PC}$ and $120 \mathrm{BPH}$ (OMIM: 600082) subjects (as a control group) were recruited in the present study. Digital rectal examination (DRE) and biopsy were also carried out due to the precise distinction between the case and control groups. The inclusion criteria are encompassing different factors, including negative biopsy report, prostate-specific antigen (PSA) $<4$, and lack of PC in the family history (control group) versus positive biopsy report and PSA $>4$ (case group). Besides, patients are exempt from any form of hormone therapy/orchiectomy or those taking PSA-influencing drugs. According to the recorded patients' medical history, clinical tumor-related data such as tumor volume, tumor weight, adhesion, vascular invasion, perineural invasion, and tumor grade/stage were assessed. The stage of the tumor and the grade of the tumor are determined by the staging of TNM (pathological tumor stage, nodal invasion, metastasis) and Gleason scoring system (GS>7, GS $\leq 7$ ), respectively $[18,19]$. A well-defined questionnaire with the information of age at diagnosis, body mass index (BMI), cancer family history, smoking habits, use of medications, DRE status, tumor grade/stage, and PSA serum level was completed for each case. At the time of diagnosis, the serum PSA rate was assessed. Patients who missed some of these data in their questionnaire considered missing data in our analysis. 


\section{AR Genotyping:}

Peripheral blood samples were collected from study subjects in EDTA-containing tubes. Genomic DNA was extracted according to the standard salting-out method [20].

$A R$ targeted region (NM_000044.4) covering 771 base pairs (bps) intragenic region containing a part of intron seven, whole exon eight and part of $3^{\prime}$ untranslated region was amplified by Polymerase Chain Reaction (PCR) by the following primers: Forward primer: 5'- TTG AGT CAT GTT CAT GTG AGT TTG T -3' and reverse primer: 5'- AGG GTT AGA TAG GGA GGG AAG AA-3' designed by Primer3 online software (V.0.4.0). The PCR was carried out in a total volume of $25 \mu \mathrm{L}$ containing DNA template $1 \mu \mathrm{L}$, primers $1 \mu \mathrm{L}$ each, $10 \mu \mathrm{L}$ Red Master Mix $2 \mathrm{mM}$, and $12 \mu \mathrm{L}$ H2O. DNA amplification was performed in a Peqlab peqSTAR2X thermal cycler (Darmstadt, Germany). Thermal cycling was initiated with the first denaturation step of 5 minutes at $95^{\circ} \mathrm{C}$, followed by 35 cycles of denaturation at $95^{\circ} \mathrm{C}$ for 50 seconds and annealing at $58^{\circ} \mathrm{C}$ for 50 seconds, extension at $72^{\circ} \mathrm{C}$ for 50 seconds with a final extension at $72^{\circ} \mathrm{C}$ for 5 minutes. The amplified PCR products were analyzed using the Sanger sequencing method and confirmed by CodonCode Aligner Software (V.8.0.2).

\section{Statistical analysis:}

Categorical and continuous variables were compared between groups using Chi-square (degree of freedom=2), independent t-test, and Fisher's exact tests. All statistical analyses were performed by Stata SE version 11 software. The $p$-value of less than 0.05 was considered statistically significant.

\section{Results}

Totally, 241 individuals (121 RP patients and $120 \mathrm{BPH}$ subjects as controls) were recruited. The mean age, weight, height, body mass index (BMI), total PSA, family history of cancer, smoking habit, and marital status were defined between case and control in (Table 1). 
Table 1

Characteristics of study subjects

\begin{tabular}{|c|c|c|c|}
\hline Characteristics & BPH & RP & $p$-value \\
\hline Age (Year) & $69.83(8.42)$ & $62.92(8.99)$ & $<0.001$ \\
\hline \multicolumn{4}{|l|}{ Mean(sd) } \\
\hline Weight (Kg) & $73.42(10.32)$ & 72.68 (10.53) & 0.582 \\
\hline \multicolumn{4}{|l|}{ Mean(sd) } \\
\hline Height (Cm) & $170.71(5.58)$ & $170.16(5.91)$ & 0.458 \\
\hline \multicolumn{4}{|l|}{ Mean(sd) } \\
\hline BMI $\left(\mathrm{Kg} / \mathrm{m}^{2}\right)$ & $25.03(3.22)$ & $25.03(3.12)$ & 1.000 \\
\hline \multicolumn{4}{|l|}{ Mean(sd) } \\
\hline Total PSA (ng/mL) & $8.01(7.21)$ & 21.55 (26.99) & $<0.001$ \\
\hline \multicolumn{4}{|l|}{ Mean(sd) } \\
\hline Family history & $0(0.0)$ & $15(12.3)$ & $<0.001$ \\
\hline \multicolumn{4}{|l|}{ No. (\%) } \\
\hline Smoking & $9(7.5)$ & $19(15.7)$ & 0.047 \\
\hline \multicolumn{4}{|l|}{ No. (\%) } \\
\hline Marital status & $0(0.0)$ * & $1(0.8)$ & 1.000 \\
\hline \multirow[t]{2}{*}{ No. (\%) } & $118(98.3)$ ** & $119(98.3)$ & \\
\hline & 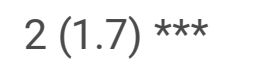 & $1(0.8)$ & \\
\hline
\end{tabular}

\section{AR Gene Mutations:}

According to the results of the amplified sequence data, 22 single nucleotide polymorphisms (SNPs) showed different frequencies for the mutant allele between case and control groups in which mutant genotype of rs113528927 was the most frequent one located on intron 7.

rs866212811 A>T and rs1045688277 A>G are the two other SNPs that have a different mutant genotype frequency between two groups, respectively after rs113528927. The rest of the SNPs are listed in (Table 2). Only one mutation naming, c.2644C $>A$, was found in exon 8 in one BPH sample. Six SNPs were determined in 3'UTR with different frequencies in which rs778492923G>A was the most frequent mutant 
genotype between the two groups. The Androgen Receptor Gene Mutations Database, SNP and ClinVar databases in NCBI, Iranome, Ensembl and UCSC Genome Browsers, HGMD database, and previous related studies were searched and reviewed to find all genetic variations in $A R$-LBD which contained 124 variants in intron 7, 44 variations and mutations in exon 8 and 52 genetic variants in $3^{\prime} U T R$ listed in (Suppl. 1). Based on Iranome, 90 AR genetic variations have been found by performing whole-exome sequencing (WES) on 800 healthy individuals from eight major ethnic groups. Only six variations have been reported previously in the Iranian population in $A R$-LBD. All these variations frequencies are listed in (Table 3). None of the six previously reported variations in the mutant form found in the present study. 
Table 2

List of SNPs and mutations found in AR-LBD target site with their frequency between RP and BPH groups.

\begin{tabular}{|c|c|c|c|}
\hline $\begin{array}{l}\text { Variant number } \\
\text { (Wild type>Mutant) }\end{array}$ & Location & $\begin{array}{l}\text { Number of Mutant allele } \\
\text { in RP group } \\
\text { (Mutant genotype) }\end{array}$ & $\begin{array}{l}\text { Number of Mutant allele in } \\
\text { BPH group } \\
\text { (Mutant genotype) }\end{array}$ \\
\hline rs1197689322 G>C & \multirow[t]{22}{*}{ Intron 7} & $0(\mathrm{C})$ & $1(\mathrm{C})$ \\
\hline rs1489745240 T>A & & $1(\mathrm{~A})$ & $0(\mathrm{~A})$ \\
\hline rs868275182 G>C & & $1(\mathrm{C})$ & $2(\mathrm{C})$ \\
\hline rs200708389 C>G & & $1(\mathrm{G})$ & $3(\mathrm{G})$ \\
\hline rs866212811 A>T & & $37(\mathrm{~T})$ & $35(T)$ \\
\hline rs867058337 G>C & & $2(\mathrm{C})$ & $3(\mathrm{C})$ \\
\hline rs867561241 A>T & & $1(\mathrm{~T})$ & $1(\mathrm{~T})$ \\
\hline rs866504983 G>A & & $1(\mathrm{~A})$ & $2(A)$ \\
\hline rs1045688277 A>G & & $10(\mathrm{G})$ & $12(\mathrm{G})$ \\
\hline rs1427499294 G>C & & $1(\mathrm{C})$ & $0(\mathrm{C})$ \\
\hline rs769636082 C>T & & $3(\mathrm{~T})$ & $0(\mathrm{~T})$ \\
\hline rs1014198095 C>T & & $1(\mathrm{~T})$ & $0(\mathrm{~T})$ \\
\hline rs1053295324 G>A & & $2(A)$ & $0(\mathrm{~A})$ \\
\hline rs893262869 C>G & & $1(\mathrm{G})$ & $0(\mathrm{G})$ \\
\hline rs1011847242 G>A & & $2(\mathrm{~A})$ & $0(\mathrm{~A})$ \\
\hline rs1426350380 G>A & & $1(\mathrm{~A})$ & $0(\mathrm{~A})$ \\
\hline rs1286850331 InsAACACA & & 1 (AACACA) & 0 (AACACA) \\
\hline rs1383090925 T>A & & $1(\mathrm{~A})$ & $0(\mathrm{~A})$ \\
\hline rs866891550 T>A & & $2(\mathrm{~A})$ & $0(\mathrm{~A})$ \\
\hline rs868405286 $A>C$ & & $2(\mathrm{C})$ & $0(\mathrm{C})$ \\
\hline $\begin{array}{l}\text { rs113528927 Dellns } \\
\text { AC>ACACACACAC }\end{array}$ & & 115 (AC>ACACACACAC) & 117 (AC>ACACACACAC) \\
\hline rs1248234035 A>G & & $1(\mathrm{G})$ & $0(\mathrm{G})$ \\
\hline c. $2644 C>A$ & Exon 8 & $0(\mathrm{~A})$ & $1(\mathrm{~A})$ \\
\hline rs989025644 C>A & 3'UTR & $1(\mathrm{~A})$ & $0(\mathrm{~A})$ \\
\hline
\end{tabular}




\begin{tabular}{|c|c|c|c|}
\hline $\begin{array}{l}\text { Variant number } \\
\text { (Wild type>Mutant) }\end{array}$ & Location & $\begin{array}{l}\text { Number of Mutant allele } \\
\text { in RP group } \\
\text { (Mutant genotype) }\end{array}$ & $\begin{array}{l}\text { Number of Mutant allele in } \\
\text { BPH group } \\
\text { (Mutant genotype) }\end{array}$ \\
\hline rs1230525633 C>G & & $1(\mathrm{G})$ & $0(G)$ \\
\hline rs1363399121 C>A & & $5(A)$ & $2(A)$ \\
\hline rs772617461 T>C & & $2(\mathrm{C})$ & $4(\mathrm{C})$ \\
\hline rs1446464556 A>G & & $3(\mathrm{G})$ & $4(G)$ \\
\hline rs778492923 G>A & & $6(A)$ & $7(A)$ \\
\hline
\end{tabular}

Table 3

List of previously reported variations in Iranian population based on Iranome.

\begin{tabular}{|lllll|}
\hline Variant & Annotation & Allele count & Allele number & Allele frequency \\
\hline c.2608-67G>C & intron & 1 & 1598 & 0.0006258 \\
\hline $\begin{array}{l}\text { rs777185142 } \\
\text { (c.2608-6C>T) }\end{array}$ & splice region & 1 & 1600 & 0.0006250 \\
\hline $\begin{array}{l}\text { rs780838814 } \\
\text { (c.2613G>A) }\end{array}$ & synonymous & 3 & 1600 & 0.001875 \\
\hline $\begin{array}{l}\text { rs202188462 } \\
\text { (c.*28C>G) }\end{array}$ & 3' UTR & 2 & & \\
\hline rs879239848 & 3' UTR & 1 & 1586 & 0.001261 \\
(c.*158_*159insT) & & & 1510 & 0.0006623 \\
\hline c.*196C>A & 3' UTR & 1 & 1434 & 0.0006974 \\
\hline
\end{tabular}

\section{Discussion}

In developing countries, including Iran, cancer is a major public health issue, making it the third leading cause of death in Iran after cardiovascular diseases [21]. Considering the genetic risk factors for PC, men with a first-degree relative (father or brother) with PC bear twice the general population risk. However, PC's molecular cause is still unclear, and its progression involves the signaling of androgen and other apoptotic pathways $[5,22,23]$.

Androgens control normal and malignant growth and differentiation of the prostate tissue through activation of $A R$ signaling in epithelial and stromal cells, which play a crucial role in carcinogenesis and disease pathogenesis in both androgen-dependent PC and CRPC $[7,9,24]$. The AR controls the expression 
of androgen-responsive genes (including PSA) by binding and interacting with other transcription factors [25].

$\mathrm{PC}$ at an early stage can be asymptomatic and requires minimal or even no treatment. $A R$ mutations tend to be a late occurrence in the $\mathrm{PC}$ as metastatic tumors have high percentages of $A R$ variations compared to primary tumors, which could be due to resistance to endocrine therapy [26-29].

Any alteration of $A R$ activation in PC may be associated with somatic or germline mutations, resulting in widespread ligand specificity and AR activation by poor adrenal androgens and other steroid hormones, including DHEA, progesterone, estrogen, and glucocorticoids, as well as in turning antagonists into agonists [9].

According to HGMD, 648 mutations were reported in the $A R$ gene, and among them, missense/nonsense mutation type constitutes the majority $(400 / 648,61.72 \%)$ of reported mutations. According to the latest update released by Androgen Receptor Gene Mutations Database in 2012, there are 159 specific

mutations found in the $A R$, mostly somatic mutations. The most common mutation site is the LBD, where approximately half of the mutations were found, followed by exon 1, where $30 \%$ of $A R$ mutations occur $[13,30,31]$. The first and most widely known mutation in the $A R$ is the T878A (rs137852578) induced by Flutamide [25, 32-34]. The F877L-mutated $A R$ (rs1057519864) was observed in patients with CRPC progressing with Enzalutamide or Apalutamide and is therefore activated by Flutamide, Enzalutamide, and Apalutamide in PC experimental models $[35,36]$.

H875Y (rs137852581) and T878A (rs137852578) AR mutations were identified in patients progressing on Abiraterone or had previously received it [35]. None of these common mutations were observed in this study, but 22 SNPs were reported, and the genotype frequency of them was different among cases and controls. Rs113528927, located on intron 7, was the most frequent one. Rs866212811 and rs1045688277 were more frequent compared to the remaining SNPs.

Precision (personalized) medicine is an emerging approach to prediction, early prevention, and treatment that takes human gene variability into account for each individual. It aims at optimizing benefits and minimizing harms for a stronger clinical target for patients. In cancer-targeted treatment, this method's therapeutic advantages are already realized, and its effect on other conditions needs further research in different societies [37].

One of PC's main challenges is related to its high heterogeneity, which makes clinical stratification and selecting treatment strategies complicated [38]. Knowledge of somatic mutations in each population could be vital for customizing medical decisions and drug administration. In respect to PC, personalized medicine's main strategies are focused on a gene-based approach to PC prevention, specifically, in susceptibility alleles in genes $A R, B R C A 1, C H E K 2, N B S 1$, and $H O X B 13$ that can improve the performance of the PSA test in a population-based setting [39]. 
So, if somatic mutation information was added to the screening program, we could improve the treatment approach in a precise manner [40]. Patients with metastatic disease are treated by androgen deprivation therapy (ADT) that with time results in the development of CRPC, usually established as metastases within bone tissue. The $A R$ mutations are the main driver of CRPC development that consequently, lead to resistance to drugs given for the treatment of CRPC [9].

In this study, we sought to investigate the $A R$ common mutation frequency in RP and BPH subjects and further find an association between these mutations and resistance to targeted therapy in the metastatic state of PC in our future studies. BPH subjects are considered as control group since they are not cancerous patients. Because of more than half of the mutations detected in the LBD site of $A R$ and the impact of this site for targeted therapy of PC patients, we considered the LBD site for mutation screening for the first time in Iranian population concerning the personalized medicine approach. In Iran, any relationship between GGN repeat length in the first exon of the $A R$ gene and idiopathic male infertility has been investigated in Iran's southwest [41].

No related study on $A R$-LBD mutations was done in the Iranian population. Since the Iranome data arise from the investigation of healthy individual samples in Iran, the negative results of this study for these variations seem correct. Other more frequent variations, rs 113528927, rs866212811, and rs 1045688277 on intron 7, may be considered an effective screening factor in PC patients and may be associated with $P C$ in the Iranian population. So, further investigation on these variants in a large sample size is highly recommended. Several studies in Caucasian patients have addressed the frequency of $A R$ mutations in primary organ-confined, advanced or metastatic tumors before and after hormonal therapy and their disease relevance. The $A R$ mutation frequency varies significantly among different studies, up to $25 \%$ in androgen-dependent tumors and up to $50 \%$ in metastatic hormone-refractory tumors $[13,42,43]$.

The results of this study provide critical information for both screening and personalized treatment of resistance PC in Iranian men with RP and BPH for the first time. Screening tests can identify people who may have a chance of disease development before detection and any symptoms.

In conclusion, our study provides new insight into $A R$ genetic screening in Iranian patients affected with PC. Moreover, further studies with a large-scaled sample size should be conducted to detect the role of $A R$ mutations in PC development and personalized treatment approach.

\section{Declarations}

\section{Funding:}

The authors declare that no funds, grants, or other support were received during the preparation of this manuscript.

\section{Author Contributions:}


[Marzieh Rahbaran and Maryam Hassani Doabsari] performed experiments and co-wrote the paper. [Mahdi Afshari] analyzed data. [Farshad Sharifi] performed statistical analysis. [Mandana Hasanzad] designed experiments, supervised the research and provided critical revision of the paper.

\section{Compliance with Ethical Standards:}

\section{Disclosure of potential conflicts of interest:}

The authors have no relevant financial or non-financial interests to disclose.

\section{Ethical approval for research involving human participants:}

This study was performed in line with the principles of the Declaration of Helsinki. Approval was granted by the Ethics Committee of Islamic Azad University Tehran Medical Sciences Committee (Ethics Codes: IR.IAU.PS.REC.1397.124 and IR.IAU.PS.REC.1397.304).

\section{Informed consent:}

Written informed consent was obtained from the patients.

\section{Acknowledgements:}

We thanks to the all study subjects whose contribution helped us to perform the study as well as possible.

\section{References}

1. Sung H, Ferlay J, Siegel RL, Laversanne M, Soerjomataram I, Jemal A, et al (2021). Global cancer statistics 2020: GLOBOCAN estimates of incidence and mortality worldwide for 36 cancers in 185 countries. CA: a cancer journal for clinicians.

2. Lotfi MM, Beheshti RM, Rouhezamin MM, Rezaianzadeh A Md MPHP, Farhadi PM, Daneshi ZM (2018). A Ten-Year Study of Prostate Cancer: A Southern Iranian Experience. Iran J Med Sci. 43(4):372-9.

3. Hassanipour S, Fathalipour M, Salehiniya $H$. The incidence of prostate cancer in Iran: a systematic review and meta-analysis (2018). Prostate international. 6(2):41-5.

4. Weng H, Li S, Huang JY, He ZQ, Meng XY, Cao Y, et al (2017). Androgen receptor gene polymorphisms and risk of prostate cancer: a meta-analysis. Sci Rep. 7:40554.

5. Alvarez-Cubero MJ, Martinez-Gonzalez LJ, Robles-Fernandez I, Martinez-Herrera J, Garcia-Rodriguez G, Pascual-Geler M, et al (2017). Somatic Mutations in Prostate Cancer: Closer to Personalized Medicine. Molecular diagnosis \& therapy. 21(2):167-78.

6. Rebbeck TR. Prostate Cancer Genetics: Variation by Race, Ethnicity, and Geography (2017). Seminars in radiation oncology. 27(1):3-10. 
7. Crona DJ, Whang YE (2017). Androgen Receptor-Dependent and -Independent Mechanisms Involved in Prostate Cancer Therapy Resistance. Cancers (Basel). 9(6).

8. Holdcraft RW, Braun RE (2004). Androgen receptor function is required in Sertoli cells for the terminal differentiation of haploid spermatids. Development. 131(2):459-67.

9. Jernberg E, Bergh A, Wikstrom P (2017). Clinical relevance of androgen receptor alterations in prostate cancer. Endocr Connect. 6(8):R146-R61.

10. Lallous N, Volik SV, Awrey S, Leblanc E, Tse R, Murillo J, et al (2016). Functional analysis of androgen receptor mutations that confer anti-androgen resistance identified in circulating cell-free DNA from prostate cancer patients. Genome Biol. 17:10.

11. Brinkmann AO (2001). Molecular basis of androgen insensitivity. Mol Cell Endocrinol. 179(1-2):105-9.

12. Eisermann K, Wang D, Jing Y, Pascal LE, Wang Z (2013). Androgen receptor gene mutation, rearrangement, polymorphism. Transl Androl Urol. 2(3):137-47.

13. Gottlieb B, Beitel LK, Nadarajah A, Paliouras M, Trifiro M (2012). The androgen receptor gene mutations database: 2012 update. Hum Mutat. 33(5):887-94.

14. Rathkopf DE, Smith MR, Ryan CJ, Berry WR, Shore ND, Liu G, et al (2017). Androgen receptor mutations in patients with castration-resistant prostate cancer treated with apalutamide. Annals of oncology : official journal of the European Society for Medical Oncology. 28(9):2264-71.

15. Hay CW, McEwan IJ (2012). The impact of point mutations in the human androgen receptor: classification of mutations on the basis of transcriptional activity. PLoS One. 7(3):e32514.

16. Tan MH, Li J, Xu HE, Melcher K, Yong EL (2015). Androgen receptor: structure, role in prostate cancer and drug discovery. Acta Pharmacol Sin. 36(1):3-23.

17. Zaman N, Giannopoulos PN, Chowdhury S, Bonneil E, Thibault P, Wang E, et al (2014). Proteomiccoupled-network analysis of T877A-androgen receptor interactomes can predict clinical prostate cancer outcomes between White (non-Hispanic) and African-American groups. PLoS One. 9(11):e113190.

18. Epstein Jl, Allsbrook WC, Jr., Amin MB, Egevad LL, Committee IG (2005). The 2005 International Society of Urological Pathology (ISUP) Consensus Conference on Gleason Grading of Prostatic Carcinoma. Am J Surg Pathol. 29(9):1228-42.

19. Hoedemaeker RF, Vis AN, Van Der Kwast TH (2000). Staging prostate cancer. Microscopy Research and Technique. 51(5):423-9.

20. Miller SA, Dykes DD, Polesky HF (1988). A simple salting out procedure for extracting DNA from human nucleated cells. Nucleic Acids Res. 16(3):1215.

21. Pakzad R, Rafiemanesh H, Ghoncheh M, Sarmad A, Salehiniya H, Hosseini S, et al (2016). Prostate Cancer in Iran: Trends in Incidence and Morphological and Epidemiological Characteristics. Asian Pac J Cancer Prev. 17(2):839-43.

22. Benafif S, Eeles R (2016). Genetic predisposition to prostate cancer. British medical bulletin. 120(1):75-89. 
23. Kiciński M, Vangronsveld J, Nawrot TS (2011). An epidemiological reappraisal of the familial aggregation of prostate cancer: a meta-analysis. PloS one. 6(10).

24. Yu J, Yu J, Mani R-S, Cao Q, Brenner CJ, Cao X, et al (2010). An integrated network of androgen receptor, polycomb, and TMPRSS2-ERG gene fusions in prostate cancer progression. Cancer cell. 17(5):443-54.

25. Taplin ME, Bubley GJ, Shuster TD, Frantz ME, Spooner AE, Ogata GK, et al (1995). Mutation of the androgen-receptor gene in metastatic androgen-independent prostate cancer. N Engl J Med. 332(21):1393-8.

26. Chan JM, Gann PH, Giovannucci EL (2005) Role of diet in prostate cancer development and progression. Journal of Clinical Oncology. 23(32):8152-60.

27. Perdana NR, Mochtar CA, Umbas R, Hamid A (2016). The risk factors of prostate cancer and its prevention: a literature review. Acta Med Indones. 48(3):228-38.

28. Rawla P (2019). Epidemiology of Prostate Cancer. World J Oncol. 10(2):63-89.

29. Suzuki H, Akakura K, Komiya A, Aida S, Akimoto S, Shimazaki J (1996). Codon 877 mutation in the androgen receptor gene in advanced prostate cancer: relation to antiandrogen withdrawal syndrome. The Prostate. 29(3):153-8.

30. Abeshouse A, Ahn J, Akbani R, Ally A, Amin S, Andry CD, et al (2015). The molecular taxonomy of primary prostate cancer. Cell. 163(4):1011-25.

31. Carver BS, Chapinski C, Wongvipat J, Hieronymus H, Chen Y, Chandarlapaty S, et al (2011). Reciprocal feedback regulation of PI3K and androgen receptor signaling in PTEN-deficient prostate cancer. Cancer cell. 19(5):575-86.

32. Fenton MA, Shuster TD, Fertig AM, Taplin M-E, Kolvenbag G, Bubley GJ, et al (1997). Functional characterization of mutant androgen receptors from androgen-independent prostate cancer. Clinical cancer research. 3(8):1383-8.

33. Taplin ME, Bubley GJ, Ko YJ, Small EJ, Upton M, Rajeshkumar B, et al (1999). Selection for androgen receptor mutations in prostate cancers treated with androgen antagonist. Cancer research. 59(11):2511-5.

34. Veldscholte J, Ris-Stalpers C, Kuiper G, Jenster G, Berrevoets C, Claassen E, et al (1990). A mutation in the ligand binding domain of the androgen receptor of human LNCaP cells affects steroid binding characteristics and response to anti-androgens. Biochemical and biophysical research communications. 173(2):534-40.

35. Azad AA, Volik SV, Wyatt AW, Haegert A, Le Bihan S, Bell RH, et al (2015). Androgen Receptor Gene Aberrations in Circulating Cell-Free DNA: Biomarkers of Therapeutic Resistance in CastrationResistant Prostate Cancer. Clin Cancer Res. 21(10):2315-24.

36. Joseph JD, Lu N, Qian J, Sensintaffar J, Shao G, Brigham D, et al (2013). A clinically relevant androgen receptor mutation confers resistance to second-generation antiandrogens enzalutamide and ARN-509. Cancer discovery. 3(9):1020-9. 
37. Hasanzad M, Sarhangi N, Aghaei Meybodi HR, Nikfar S, Khatami F, Larijani B (2019). Precision Medicine in Non Communicable Diseases. International Journal of Molecular and Cellular Medicine. 8(2):1-18.

38. Barbieri CE, Tomlins SA, editors (2014). The prostate cancer genome: perspectives and potential. Urologic Oncology: Seminars and Original Investigations; Elsevier.

39. Cybulski C, Wokołorczyk D, Kluźniak W, Kashyap A, Gołąb A, Słojewski M, et al (2013). A personalised approach to prostate cancer screening based on genotyping of risk founder alleles. British journal of cancer. 108(12):2601-9.

40. Jackson SE, Chester JD (2015). Personalised cancer medicine. International journal of cancer. 137(2):262-6.

41. Dai X, Fang X, Ma Y, Xianyu J (2016). Benign Prostatic Hyperplasia and the Risk of Prostate Cancer and Bladder Cancer: A Meta-Analysis of Observational Studies. Medicine (Baltimore). 95(18):e3493.

42. Koochekpour S (2010). Androgen receptor signaling and mutations in prostate cancer. Asian J Androl. 12(5):639-57.

43. Moghadam M, Khatami SR, Galehdari H (2015). Association of androgen receptor GGN repeat length polymorphism and male infertility in Khuzestan, Iran. Iran J Reprod Med. 13(5):305-10.

\section{Supplementary Files}

This is a list of supplementary files associated with this preprint. Click to download.

- Suppl.1.docx 